
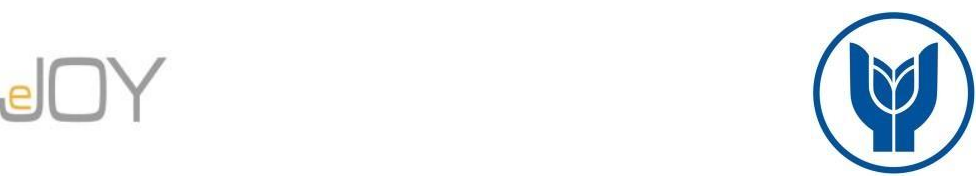

Karakaş, E. / Journal of Yasar University, 2019, 14/55, 318-328

\title{
Türkiye'nin Otomotiv İhracat Gelirinin ARIMA modeli ile Tahmin Edilmesi
}

\section{Forecasting Automotive Export Revenue of Turkey using ARIMA Model}

\author{
Esra Karakaş, Adana Alparslan Türkeş Bilim ve Teknoloji Üniversitesi, Türkiye, ekarakas@atu.edu.tr
}

\begin{abstract}
Öz: Otomotiv sanayi, ortaya çıkardı̆̆ı katma değer, istihdama katklsı, birçok sektörün gelişimine destek sağlaması ve ülkeye sağladığı ihracat geliri açısından oldukça önemli bir sanayi koludur. Otomotiv ihracat geliri tahmin verileri, sektörde yapılacak yatırımların iyi planlanması ve ihracat ile ilgili stratejik kararların verilmesi aşamasında kullanılan önemli bir bilgidir. Mevcut çalışmada, Türkiye'nin ihracat gelirini tahmin edebilecek uygun ARIMA modelinin gelişstirilmesi hedeflenmişstir. Bu amaçla, Türkiye İhracatçılar Meclisi internet sitesinden elde edilen 2013-2018 yılları arasindaki aylık otomotiv sanayi ihracat geliri verileri kullanılmıștır. Yapılan analizler neticesinde, ARIMA $(1,2,1)(0,1,1)_{12}$ modelinin tahmin için uygun olduğu ortaya konmuştur. Önerilen model kullanilarak 2019 yll ayllk ihracat geliri tahmini elde edilmişstir. Tahmin edilen değerler, 2019 yllinın Ocak, Subat,Mart ve Nisan ayları ihracat rakamları ile kıyaslandı̆̆ında, modelin gerçek değerlere yakın tahminler ortaya koyduğu görülmüstür.
\end{abstract}

Anahtar Sözcükler: Zaman serileri, ARIMA modelleri, Otomotiv ihracat

Abstract: Automotive industry has utmost importance in terms of the added value it creates, its contribution to employment, providing support to the development of many sectors, and the export revenue it provides to the country. Therefore automotive export revenue forecast data is an important piece of information used in the planning of investments in the sector and making strategic decisions. This study aims to develop an ARIMA model to forecast the export revenue of the automotive industry in Turkey. The monthly export revenue data from 2013 to 2018 is obtained from the Turkish Exporters' Assembly website. As a result of the analysis, ARIMA $(1,2,1)(0,1,1)_{12}$ model is found to be suitable for forecasting. The monthly export revenue forecast of 2019 is obtained by using the fitted model. When the predicted figures are compared with the actual export figures of January, February, and March of 2019, it is seen that forecasted figures are in line with the actual numbers.

\section{Keywords: Time series, ARIMA models, Automotive export}

\section{Giriş}

Otomotiv sanayii, yarattığı katma değer, doğrudan ve dolaylı olarak istihdama katkısı ve teknolojik gelişmeye öncülük etmesi nedeniyle ülkelerin kalkınmasında önemli bir rol oynamaktadır. Aynı zamanda demir ve çelik, lastik ve plastik, dokuma, cam, boya, elektrik ve elektronik gibi birçok sektörden girdi alması ve pazarlama, tamir, bakım ve yedek parça satışları, finansman ve sigortacılık hizmetlerinde yarattığı geniş iş hacmi nedeniyle de ekonomilerde sürükleyici bir özelliğe sahiptir (Bedir, 2002). Dolayısıyla, otomotiv sektörü gelişmiş ve gelişmekte olan ülke ekonomilerinin istikrarlı bir şekilde büyümesini sağlayan, teknolojik gelişmeleri hızlandıran ve diğer birçok sektörün büyümesine yardımcı olan lokomotif niteliğinde sektörlerdendir. (Pişkin, 2017).

Türkiye otomotiv sektörü, ihracatının öncüsü olan sektörlerdendir. Yeni ürün ve kapasite yatırımlarıyla üretim ve ihracat rakamlarını her yıl biraz daha artırarak dünya pazarındaki yükselişini sürdürmektedir. 2016 yılı verilerine göre Türkiye \%16,1'lik artış ile üretim performansını en çok artıran ülkelerden biri haline gelmiş ve dünya sıralamasında 15 . sırada yer almıştır. Ayrıca aynı sene, Avrupa Birliği'ne yapılan motorlu taşıt ihracatında ise Japonya, Güney Kore ve Amerika Birleşik Devletleri (ABD) gibi güçlü oyuncuları geride bırakarak ilk sıraya çıkmıştır (Ölekli, 2018). Rakamlar, 2017 ve 2018 içinde büyümenin devam ettiğini göstermiştir. 2018 yılı Ocak-Ekim döneminde bir önceki yılın aynı dönemine göre, toplam otomotiv ihracatı dolar bazında \%13, euro bazında ise \%6 artmıştır (Otomotiv Sanayii Derneği, 2018).

Diğer birçok üretim sektörü için olduğu gibi otomotiv sektörü içinde doğru ihracat tahmin verileri elde etmek, üretim seviyelerinin belirlenmesi, kapasite artırımı kararlarının alınabilmesi ve hatta devlet teşvik planlarının yapılabilmesi için oldukça önemlidir. Mevcut çalışma kapsamında, Türkiye'nin önemli ihracat kalemlerinden birini oluşturan otomotiv sanayi ihracat gelirini tahmin etmek için zaman serisi yöntemlerinden Box-Jenkins yöntemine dayalı ARIMA modeli geliştirilmiştir. Türkiye İhracatçılar Meclisi sayfasında yayınlanan, 2013-2018 yılları arasındaki aylık otomotiv ihracat rakamları kullanılmıştır (Türkiye İhracatçılar Meclisi, t.y.) ARIMA modelleri genel olarak otoregresif birleştirilmiş hareketli ortalamalar (autoregressive integrated moving average, ARIMA) modelleridir. ARIMA modelleri hem durağan hem de durağan olmayan serilere uygulanabilmesi açısından avantajlıdır.

Literatürde, ihracat miktarlarının tahmin edilmesinde, farklı yaklaşımların uygulandığı görülmektedir. Tahmin miktarına etki edebilecek bazı değişkenlerin dikkate alındığı regresyon analizi, yapay sinir ağları gibi yöntemler kullanıldığı gibi; sadece geçmiş ihracat rakamlarından yola çıkarak tahminin yapılan farklı zaman serisi modelleri de kullanılmaktadır. Mevcut bölümde, ihracat tahminine yönelik çalışmalar özetlenmiştir. 
Ersungur, Kızıltan ve Polat (2006), Türkiye ithalat ve ihracat serilerinin yapısal analizlerinin ve 2006 yılı tahminin ortaya konmasında ARIMA modelleri kullanmışlardır. Zaman serisi analizleri neticesinde, 1994, 2000 ve 2001 y1llarında krizlerin etkisiyle hem ihracat hem de ithalat düzeyinde azalmalar olduğu ortaya konmuştur. Kargbo (2007), Güney Afrika'nın tarım ihracat ve ithalat tahmin değerlerini elde edebilmek için; üstel düzeltme, ARIMA modeli, vektör otoregresyon (VAR), vektör hata düzetlme modeli (VECM) ve Engle-Granger (E-G) yöntemini kullanmışlardır. ARIMA ve E-G yönteminin diğer yöntemlere göre daha iyi sonuç verdiğini ortaya koymuşlardır. Co ve Boosarawongse (2007), Tayland'ın pirinç ihracat değerinin tahmin edilmesi için üstel düzeltme, ARIMA modeli ve yapay sinir ağı modellerini kullanmışlar ve sonuçları kıyaslamışlardır. Keck, Raubold ve Truppia (2010), ihracattaki büyümeyi tahmin etmek için hem zaman serisi analizi hem de ekonomik teoriye dayalı ek öngörücüler içeren yapısal yaklaşımlar kullanılmıştır. Sonuçlar değerlendirildikten sonra çalışmanın karmaşık makroekonomik modeller için bir referans noktası olabileceği vurgulanmıştır. Wong, Tu ve Wang (2010), Tayvan ihracat rakamlarının tahmini için bulanık zaman serisi ve klasik zaman serisi olamk üzere iki yöntem kullanmış ve elde edilen sonuçları kıyaslamışlardır. Kısa dönemli tahminlerde bulanık zaman serisi yönteminin, uzun dönemli tahminlerde ise ARIMA modelinin daha iyi sonuç verdiğini göstermişlerdir. Bu çalışmaya benzer olarak, Wang (2011) de, Tayvan ihracat miktarının tahmin edilmesi için ARIMA zaman serisi yöntemi ve bulanık zaman serisi yöntemi olmak üzere iki farklı yöntem uygulamıştır. Ocak 1990 ile Mart 2002 arasındaki zaman diliminde Tayvan ihracat miktarı verilerini dikkate alınarak tahmin modelleri oluşturulmuş ve iki yöntemden elde edilen sonuçlar kıyaslanmıştır. Ozbek, Akalın, Topuz ve Sennaroglu (2011), Türkiye'nin kot pantolon ihracatını tahmin etmek için yapay sinir ağları ve ARIMA modellerini uygulamıştır. Yapay sinir ağları modelinde, kot pantolon ithalatı, asgari ücret, pamuk, su ve elektrik fiyatı, TL'nin ABD doları karşısındaki değeri, hazır giyim işletmelerinin kredi kullanımı, kot pantolon markaları, reel efektif döviz kuru gibi değişkenler dikkate alınmıştır. Her iki modelden elde edilen sonuçlar kıyaslanmış ve tartışılmıştır. Paul, Panwar, Sarkar, Kumar, Singh, Farooqui ve Choudhary (2013), Hindistan'ın et ihracatını tahmin edebilmek amacıyla Kasım 1992 ve Aralık 2011 arasındaki aylık zaman serisi değerlerini kullanarak uygun ARIMA modelini geliştirmişlerdir. Model hataları grafiğinin yanısıra, belirledikleri tahmin hatası ölçütlerini dikkate alarak modellerinin uygun bir tahmin edici olduğunu belirtmişlerdir. Farooqi (2014), Pakistan ithalat ve ihracat rakamlarını tahmin etmek için, Pakistan'ın 1947-2013 yılları arasındaki ithalat ve ihracat rakamlarını kullanarak uygun ARIMA modelini geliştirmiş ve test etmiştir. Karahan (2015), yapay sinir ağı modeli kullanılarak, Malatya ili kuru kayısı ürününe ait ihracat miktarlarının tahminini gerçekleştirmiştir. Uygulama sonrası yaptıkları hata testi sonuçlarına dayanarak modelin yaptığı tahminlerin güvenilir ve tutarlı olduğunu belirtmişlerdir. Lu (2015), 1989 ve 2014 yılları arasındaki Amerika tekstil ihracat verilerini dikkate alarak ihracat miktarının tahmini için; regresyon analizi ve ARIMA modeli olmak üzere iki farklı yöntem ortaya koymuştur. Sonuç olarak, iki yönteminde birbirleriyle aynı tahmin değerlerini verdiğini belirtmiştir. Uysal ve Karabat (2017), Türkiye'de kuru üzüm ihracatını tahmin etmek için bir zaman serisi modelleme yaklaşımı olan Çift Üstel Düzeltme yöntemini kullanılmıştır. Mevcut çalışmada 1982-2015 yıllarındaki yıllık veriler kullanılarak Türkiye'de kuru üzüm ihracatı için beş yıllık tahmin yapılmıştır. Chaiwuttisak (2018), otomobil endüstrisinin ihracat değerini tahmin edebilmek amaciyla uygun zaman serisi yönteminin belirlenmesini hedeflemişdir. Bu amaçla, Ocak 2010 ve Aralık 2017 tarihleri arasındaki aylık otomobil endüstrisi ihracat değerleri verilerini kullanarak, üstel düzeltme ve ARIMA modeli olmak üzere iki farklı zaman serisi yöntemi ile tahmin değerilerini elde etmişlerdir. Sonuçların kıyaslanması neticesinde, ARIMA modelinin daha iyi sonuç verdiğini belirtmiştir. Ersen ve Bayram (2019), kağıt ve kağıt ürünleri ihracat ve ithalat değerlerinin tahmin edilmesi için, Ocak 2003 ve Aralık 2014 arasındaki aylık verileri kullanrak uygun ARIMA modelinin belirlenmesini amaçlamışlardır. Analizler neticesinde, ihracat ve ithalat değerleri tahmini için $\operatorname{ARIMA~}(2,1,0)(0,0,1) 12$ ve $\operatorname{ARIMA}(3,1,2)(1,0,1)_{12}$ modellerinin uygun olduğunu ortaya koymuşlardır. Ortalama mutlak yüzde hata değerlerini dikkate alarak, ARIMA $(2,1,0)(0,0,1) 12$ modelinin oldukça iyi bir tahmin edici olduğu ve $\operatorname{ARIMA}(3,1,2)(1,0,1)_{12}$ modelinin ise iyi bir tahmin edici olduğunu ortaya koymuşlardır.

\section{Yöntem}

Bir zaman serisi, zaman içerisinde sıralanmış ölçümlerinin bir kümesidir. Zaman serisi analizi zamansal ölçümlerin yapıldığı her alanda kullanılmaktadır. Örneğin, aylık satış miktarı, aylık enflasyon oranı, aylık ihracat ve ithalat miktarları, aylık yağış miktarı gibi veriler zaman serilerine birer örnektir. Zaman serileri analizini gerçekleştirebilmek için yeterli sayıda ve güvenilir veriye ihtiyaç vardır. Ayrıca, mevcut veriler ile en doğru tahmini gerçekleştirebilmek en uygun zaman serisi yönteminin belirlenmesi gerekir. En sık kullanılan zaman serisi yöntemleri, ağırlıklı ortalama yöntemleri, üstel düzeltme, Holt-Winters, trend analizi, ayrıştırma ve Box-Jenkins yöntemleridir.

Mevcut çalışmada Box-Jenkins yöntemi kullanılmıştır. Box-Jenkins yöntemleri, otoregresif birleştirilmiş hareketli ortalamalar (autoregressive integrated moving average, ARIMA) olarak adlandırılmıştır. ARIMA modelleri hem durağan hem de durağan olmayan serilere uygulanabilmesi açısından avantajlıdır. ARIMA modellerinin uygulanabilmesi için belirli adımların uygulanması gerekir. Bu temel adımlar şu şekilde özetlenebilir (Hanke ve Wichern, 2014: 407-411);

a. Zaman serisinin durağan olup olmadığını belirlenmesi ve eğer durağan değilse durağan hale getirmek için serilerin yeteri sayıda farkının alınması,

b. Kullanılacak modelin formunun belirlenmesi yani serinin $\operatorname{AR}(\mathrm{p})$ veya $\mathrm{MA}(\mathrm{q})$ modellerinden hangisine uyduğunun ortaya konulması,

c. Elde edilen ve tahminin yapılmasında kullanılan modele ait parametrelerin istatistiksel olarak anlamlı olup olmadikları test edilmesi,

d. Modelin yetersiz olması durumunda, revize edilmesi veya diğer bir ifade ile alternatif modellerin dikkate alınması ve yukarıdaki adımların tekrarlanması. 
Uygun ARIMA modeli belirlenirken temel amaç en az sayıda parametre içeren en uygun formun belirlenmesidir. Alt bölümlerde sırasıyla AR, MA ve ARIMA ve SARIMA modelleri tanıtılmıştır.

\subsection{Otoregresif Modeller (AR)}

AR modelleri, zaman serisinin herhangi bir dönemdeki gözlem değerini, serinin önceki dönemlerine ait belirli sayıda gözlem değerleri ve hata teriminin doğrusal bir birleşimi olarak ifade eden modellerdir. AR modeller içerdikleri geçmiş gözlem sayısına göre adlandırılır. Eğer bir geçmiş gözlem içeriyorsa birinci dereceden, iki geçmiş gözlem içeriyorsa ikinci dereceden, genel olarak ise p adet geçmiş gözlem içeriyorsa p. dereceden olarak adlandırılır (Duru, 2007: 17). AR(p) modelinin matematiksel ifadesi aşağıda verilmiştir (Hanke ve Wichern, 2014: 404):

$Y_{t}=\emptyset_{0}+\emptyset_{1} Y_{t-1}+\cdots+\emptyset_{p} Y_{t-p}+\varepsilon_{t}$

burada,

$Y_{t}, Y_{t-1}, \ldots Y_{t-p}: t, t-1, t-p$ zamanlarına ait gözlem değerleri

$\emptyset_{0}, \emptyset_{1}, \ldots \emptyset_{p}:$ tahmin edilen parametre değerleri

$\varepsilon_{t}: \mathrm{t}$ zamanına ait hata terimi

\subsection{Hareketli Ortalama (MA)}

MA modelleri, zaman serisinin herhangi bir dönemindeki gözlem değerini, aynı döneminin hata terimi ve belirli sayıda geçmiş dönemin hata terimlerinin doğrusal bir bilesimi olarak ifade eder. MA modelleri içerdikleri geçmiş dönem hata terimi sayısına göre birinci dereceden, ikinci dereceden ve genel olarak q'inci dereceden MA modelleri olarak adlandırılırlar (Duru, 2007, s. 18). Modelin genel matematiksel ifadesi aşağıda verilmiştir (Hanke ve Wichern, 2014: 405).

$Y_{t}=\mu+\varepsilon_{t}-\omega_{1} \varepsilon_{t-1}-\omega_{2} \varepsilon_{t-2}-\cdots-\omega_{q} \varepsilon_{t-q}$

burada,

$Y_{t}: t$ zamanına ait gözlem değeri

$\mu$ : sabit proses ortalamas1

$\varepsilon_{t}, \varepsilon_{t-1}, \ldots \varepsilon_{t-p}:$ hata terimleri

$\omega_{1}, \omega_{2}, \ldots, \omega_{t-p}$ : modelin katsayıları olarak ifade edilmektedir.

\subsection{Otoregresif Hareketli Ortalama Modelleri}

Birçok durumda seri tek başına $\mathrm{AR}(\mathrm{p})$ veya $\mathrm{MA}(\mathrm{q})$ süreçleri tarafından ifade edilemezler. Bu yüzden bu seriler otoregresif ve hareketli ortalama modellerinin birleşimi olan ARMA modeli şeklinde ifade edilmeye çalış1lır (Özek, 2010: 16). Genel olarak p. ve q. dereceden bir ARMA (p, q) modeli (Hanke ve Wichern, 2014: 407):

$Y_{t}=\emptyset_{0}+\emptyset_{1} Y_{t-1}+\cdots+\emptyset_{p} Y_{t-p}+\varepsilon_{t}-\omega_{1} \varepsilon_{t-1}-\omega_{2} \varepsilon_{t-2}-\cdots-\omega_{q} \varepsilon_{t-q}$

\subsection{Bütünleşik Otoregresif Hareketli Ortalama Modelleri}

Eğer seri durağan değilse, ilk adımda serinin durağan hale gelmesi için ihtiyaç duyduğu kadar farkı alınmalıdır. ARIMA modelleri ARIMA (p,d,q) ile gösterilir ve ifadedeki d sayısı, serinin durağan hale gelmesi için kaç defa farkının aldığını gösterir. Bu durumda eğer d, sıfira eşitse $\operatorname{ARIMA~}(p, 0, q)$ modeli, $\operatorname{ARMA}(p, q)$ modeli aynı yapıyı ifade eder (Hanke ve Wichern, 2014: 408).

\subsection{Mevsimsel Bütünleșik Otoregresif Hareketli Ortalama Modelleri}

ARIMA modelinin mevsimsel kısmı, mevsimsel olmayan kısım ile aynı yapıya sahiptir; bir AR faktörü, bir MA faktörü ve / veya farklılaşma terimine sahip olabilir. Mevsimsel ARIMA modeli bir ARIMA (p, d, q) x (P, D, Q) modeli olarak sınıflandırılır. Burada, P; mevsimsel otoregresif (SAR) terimini, D; mevsimsel fark sayısını, Q; mevsimsel hareketli ortalama (SMA) terimini ifade eder.

\section{Türkiye'nin Otomotiv İhracat Gelirinin Tahmini}

Türkiye otomotiv ihracat gelirini tahmin etmek amacıyla, Türkiye İhracatçılar Meclisi (TİM) internet sayfasından erişilen 2013-2018 yılları arasındaki aylık otomotiv ihracat rakamları kullanılmıştır (Türkiye İhracatçılar Meclisi, t.y.). Mevcut veriler düzenlemiş ve Tablo 1'de verilmiştir.

Tablo 1. 2013-2018 Y1lları Arası Aylık Otomativ İhracat Geliri (1000\$) 
Karakaş, E. / Journal of Yasar University, 2019, 14/55, 318-328

\begin{tabular}{|l|llllll|}
\hline \multirow{2}{*}{ Ay } & \multicolumn{5}{|c|}{ Y1llar } \\
\cline { 2 - 7 } & 2013 & 2014 & 2015 & 2016 & 2017 & 2018 \\
\hline Ocak & 1491467 & 1587012 & 1730321 & 1512312 & 2064187 & 2285575 \\
Şubat & 1787499 & 1836129 & 1705352 & 1983151 & 2227176 & 2795909 \\
Mart & 1869681 & 2127555 & 1772088 & 2046686 & 2708888 & 3144201 \\
Nisan & 1769820 & 2097242 & 1843349 & 2045827 & 2293564 & 2902145 \\
Mayıs & 1846015 & 2054498 & 1481932 & 1998451 & 2564302 & 2764175 \\
Haziran & 1805218 & 2031817 & 1975601 & 2148010 & 2495096 & 2539982 \\
Temmuz & 1964670 & 1994291 & 1644332 & 1724780 & 2431113 & 2762845 \\
Ağustos & 1266796 & 1268663 & 1363694 & 1677842 & 1833736 & 1607709 \\
Eylül & 1966208 & 1959784 & 1875320 & 1940461 & 2149862 & 2605433 \\
Ekim & 1751212 & 1713229 & 2030820 & 2211008 & 2631196 & 2919511 \\
Kasım & 2077721 & 1845222 & 1920563 & 2253549 & 2644592 & 2767722 \\
Aralık & 1764567 & 1789927 & 1849792 & 2347551 & 2490844 & 2473262 \\
\hline
\end{tabular}

Zaman serisinin durağan olup olmadığını ve sahip olduğu davranışları (trend, mevsimsellik, vs.) belirlemek için serinin grafiği, serinin otokorelasyon (ACF) ve kısmi otokorelasyon (PACF) fonksiyonlarından faydalanılmaktadır. Öncelikle, seri hakkında genel bilgi edinebilmek amacıyla zaman serisi grafiği Şekil 1'de verilmiştir.

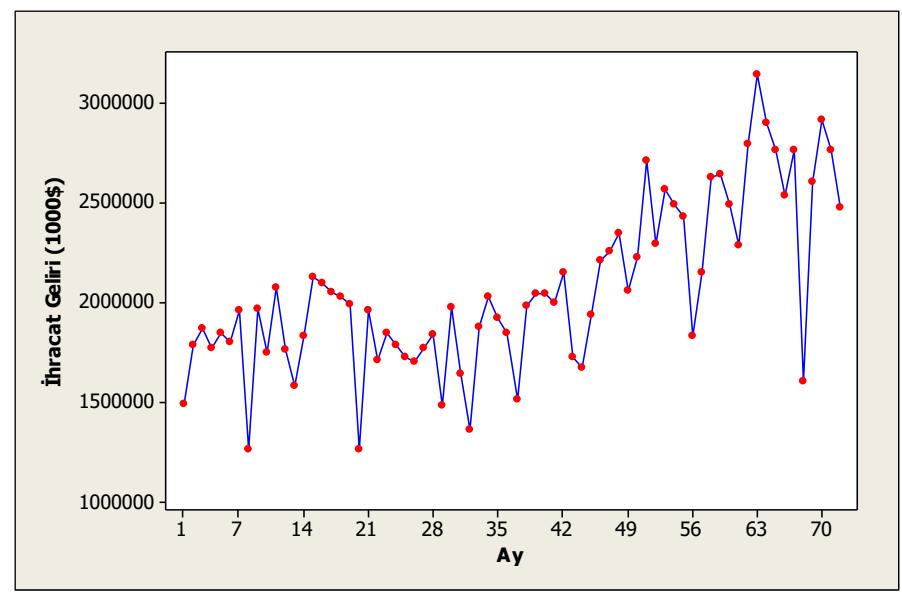

Şekil 1. Aylık Otomotiv İhracat Geliri Serisi ( 2013-2018)

Şekil 1 incelendiğinde genel anlamda serinin bir artış eğilimine (trend) sahip olduğu görülmekle birlikte belirli aylarda tekrar eden artışlar olabileceği fark edilmektedir. Bu durumda mevsimsel etkilerin de söz konusu olabileceği kanısına varılmaktadır. Mevsimsel etkileri daha net görebilmek için her bir senenin aylık verilerini ayrı ayrı içeren zaman serisi grafiğinden (Şekil 2) faydalanılmıştır.

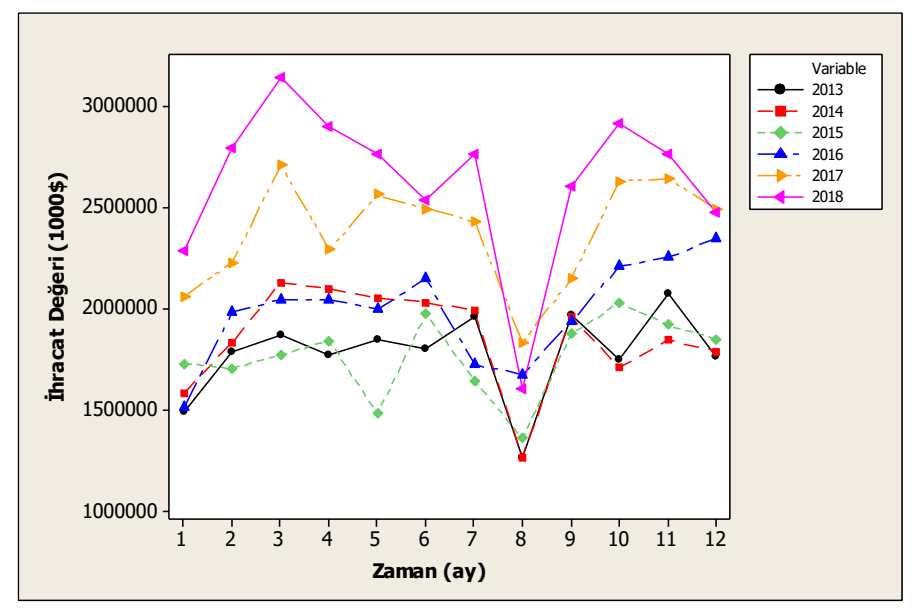


Şekil 2'de özellikle Mart, Temmuz ve Eylül aylarında diğer aylara göre artış gösterdiği görülmektedir. Bu durumda, mevcut zaman serisinin hem trend davranışına sahip olduğu hem de mevsimsel etki altında olduğuna dair genel bir bilgi elde edilmiştir. Daha detaylı analiz yapabilmek ve geçerli ARIMA modelini belirleyebilmek için uygun paket programdan faydalanılarak elde edilen otokorelasyon (ACF) fonksiyonu \%5 anlamlılık sınırları gösterilerek Şekil 3'de verilmiştir.

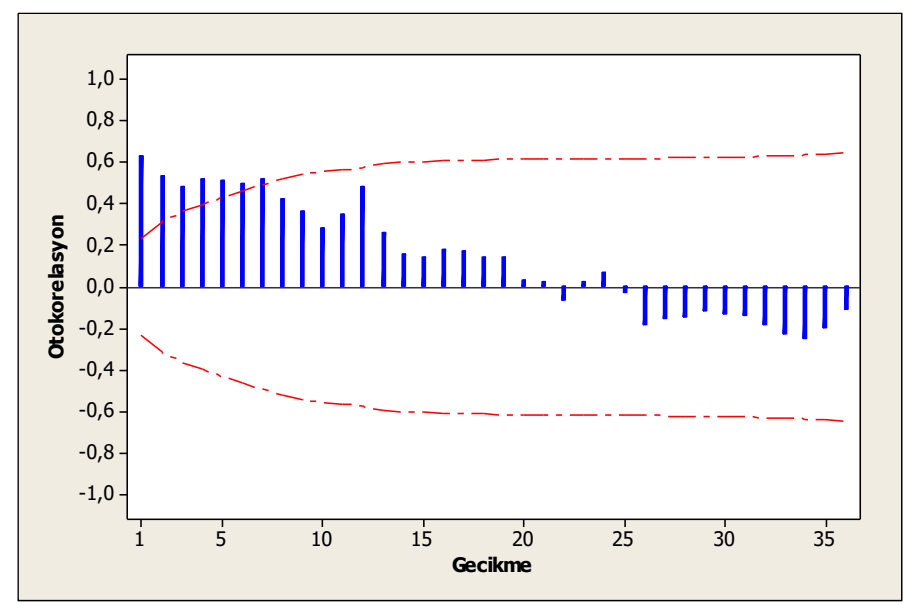

Şekil 3. Aylık Otomotiv İhracat Geliri Serisine Ait Otokorelasyon Fonksiyonu

Zaman serisinin ilk birkaç gecikmesine ait otokorelasyon değerlerinin oldukça büyük olduğu ve yavaş yavaş azaldığı göz önüne alındığında, serinin durağan olmadığı ve trend davranışına sahip olduğu anlaşılmaktadır. Ayrıca, otokorelasyon grafiğindeki sinüs dalgalanmasına benzer yapılar mevsimsel etkinin de söz konusu olabileceğini ortaya koymaktadır. Bu durumda, seriyi durağan hale getirmek için serinin ihtiyaç duyduğu kadar farkının alınması gerekmektedir. Aynı zamanda, mevcut zaman serisinde mevsimsel etkiler de söz konusu olduğu için, birinci dereceden fark seriyi durağan hale getirmek için yeterli olmayabilir ve buna ek olarak mevsimsel fark almak gerekebilir. Birinci dereceden farkı alınmış serinin otokorelasyon grafiği Şekil 4'de verilmiştir.

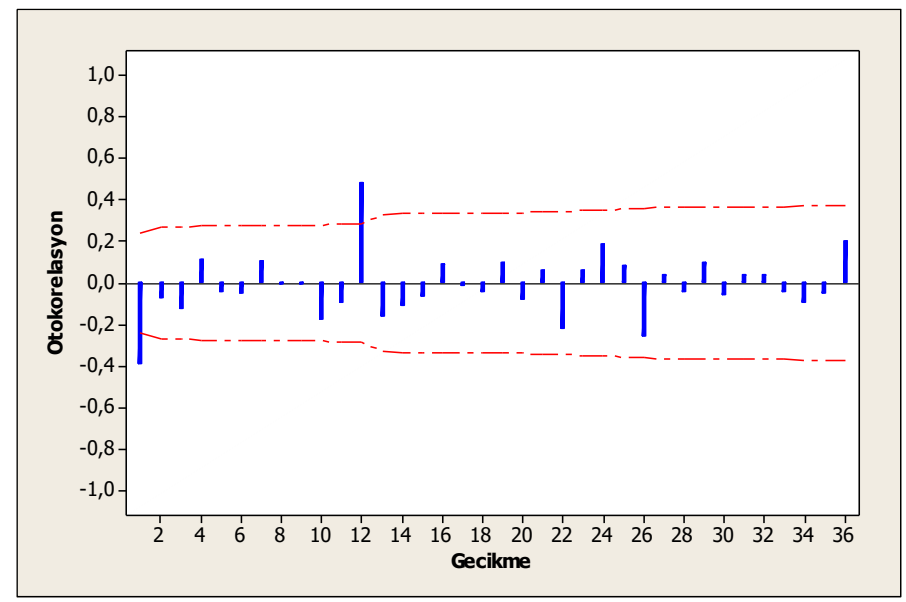

Şekil 4. Birinci Dereceden Farkı Alınmış Serinin Otokorelasyon Fonksiyonu

Birinci dereceden farkı alınmış zaman serisinin otokorelasyon grafiği incelendiğinde, özellikle birinci gecikme ve onikinci gecikme değerlerine ait otokorelasyon değerlerinin $\% 5$ anlamlılık düzeyini geçtiği gözlenmektedir (Şekil 4). Bu nedenle seriye ait mevsimselliğin de dikkate alınması gerektiği ve seriyi durağan hale getirmek için birinci dereceden farkla birlikte mevsimsel etki nedeniyle onikinci dereceden farkının da alınması gerektiği anlaşılmaktadır (Hanke ve Wichern, 2014: 428). 


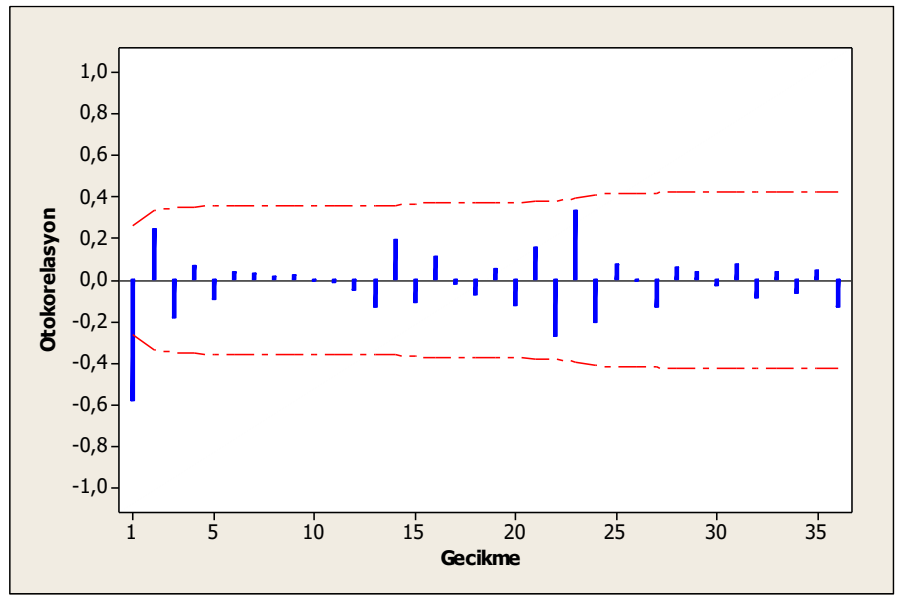

Şekil 5. Normal Düzeyde Birinci Dereceden ve Mevsimsel Farkı Alınmış Serinin Otokorelasyon Fonksiyonu

Şekil 5 ile gösterilmiş olan otokorelasyon grafiği incelendiğinde sadece ilk gecikme için otokorelasyon değerinin anlamlı bir şekilde büyük olduğu diğer değerler için \%5 anlamlılık sınırları içerisinde kaldığı görülmektedir. Ancak daha büyük gecikmeler için de anlamlılık düzeyine yakın değerler çıkması, durağanlık konusunda şüphelere neden olmaktadır. $\mathrm{Bu}$ durumda, test istatistiklerine bakılarak durağanlık şartının sağlanıp sağlanmadığına dair net sonuçları elde etmek mümkündür. Kullanılan paket program durağanlığın otokorelasyon verilerine dayalı olarak test edilmesinde kullanılan Q istatistiğini vermektedir. Q istatistiği, ilgili Ki-Kare dağılımı değeri kıyaslanır. Tablo 2'de normal düzeyde birinci dereceden ve mevsimsel farkı alınmış seriye ait otokorelasyon değerlerinin istatistikleri verilmiştir.

Tablo 2. Normal Düzeyde Birinci Dereceden ve Mevsimsel Farkı Birlikte Alınmış Serinin Test İstatistikleri

\begin{tabular}{|c|c|c|c|}
\hline Gecikme & Otokorelasyon & T-ist. & LBQ \\
\hline 1 & $-0,576686$ & $-4,43$ & 20,64 \\
\hline 2 & 0,249063 & 1,48 & 24,55 \\
\hline 3 & $-0,180045$ & $-1,03$ & 26,64 \\
\hline 4 & 0,070247 & 0,40 & 26,96 \\
\hline 5 & $-0,094985$ & $-0,53$ & 27,56 \\
\hline 6 & 0,043468 & 0,24 & 27,69 \\
\hline 7 & 0,034437 & 0,19 & 27,77 \\
\hline 8 & 0,018678 & 0,10 & 27,80 \\
\hline 9 & 0,025945 & 0,15 & 27,84 \\
\hline 10 & $-0,000238$ & 0,00 & 27,84 \\
\hline
\end{tabular}

Grafikler üzerinde mevsimsel etkilerin daha net görülebilmesi amacıyla gecikme sayıları 36'ya kadar alınmıştır. Ancak daha az sayıda otokorelasyon değeri test amacıyla yeterli olmaktadır. Tablo 2' de verilen sonuçlardan, 10 gecikme için test istatistiği değerinin 27,84 olduğu görülmektedir. 10 serbestlik derecesinde ve \% 5 anlam seviyesinde Ki-Kare istatistiği değeri ise 18,31 'dir. Bu durumda serinin durağan olmadığı anlaşılır. Seriyi durağan hale getirmek için bir fark işlemi daha yapılıp durağanlığın tekrar değerlendirilmesi gerekir. Bu amaçla, ihracat geliri serisinin iki normal düzeyde ve bir mevsimsel farkının alınmasından sonra elde edilen test istatistikleri Tablo 3' de verilmiştir.

Tablo 3. Normal Düzeyde İkinci Dereceden ve Mevsimsel Farkı Alınmış Serinin Test İstatistikleri

\begin{tabular}{|c|c|c|c|}
\hline Gecikme & Otokorelasyon & T-ist. & LBQ \\
\hline 1 & 0,104183 & 0,79 & 0,66 \\
\hline 2 & $-0,316374$ & $-2,38$ & 6,88 \\
\hline 3 & $-0,029641$ & $-0,20$ & 6,94 \\
\hline 4 & $-0,156155$ & $-1,08$ & 8,51 \\
\hline 5 & $-0,102916$ & $-0,69$ & 9,21 \\
\hline 6 & 0,033389 & 0,22 & 9,28 \\
\hline 7 & 0,133596 & 0,89 & 10,50 \\
\hline 8 & 0,105988 & 0,70 & 11,28 \\
\hline 9 & 0,081266 & 0,53 & 11,75 \\
\hline 10 & 0,021279 & 0,14 & 11,78 \\
\hline
\end{tabular}


Tablo 3'den, 10 gecikme değerinde istatistiği değerinin 11,78 olduğu anlaşılmaktadır. Bu değer, 10 serbestlik derecesinde ve $\% 5$ anlam seviyesinde Ki-Kare istatistiği olan 18,31'den küçüktür. Serinin artık durağan hale geldiğini anlaşılmaktadır. Bu durumda, durağanlık şartı sağlandığı için yeterli fark işlemi yapılmış serinin otokorelasyon (Şekil 6) ve kısmi otokorelasyon grafiklerine (Şekil 7) bakılarak uygun modelin belirlenebilir.

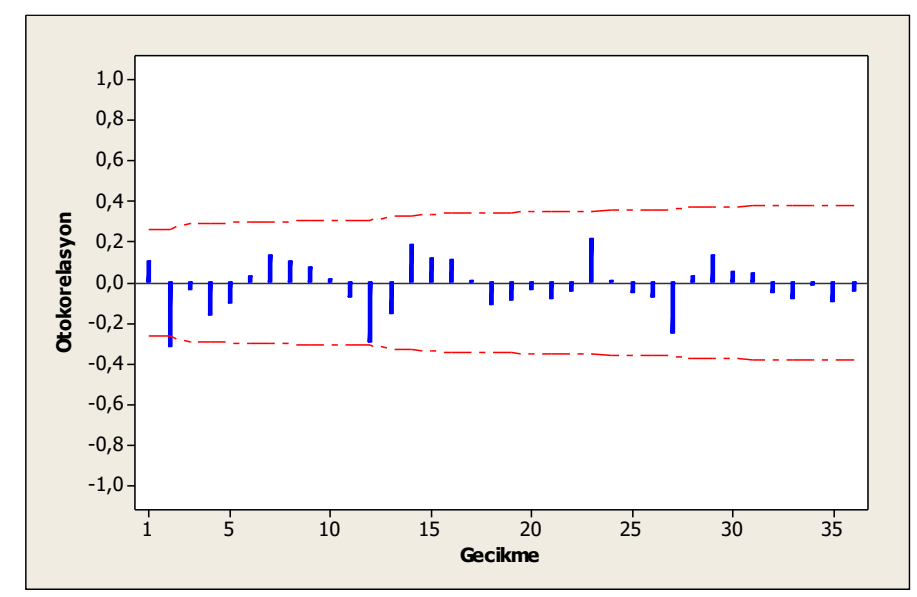

Şekil 6. Normal Düzeyde İkinci Dereceden ve Mevsimsel Farkları Alınmış Serinin Otokorelasyon Fonksiyonu

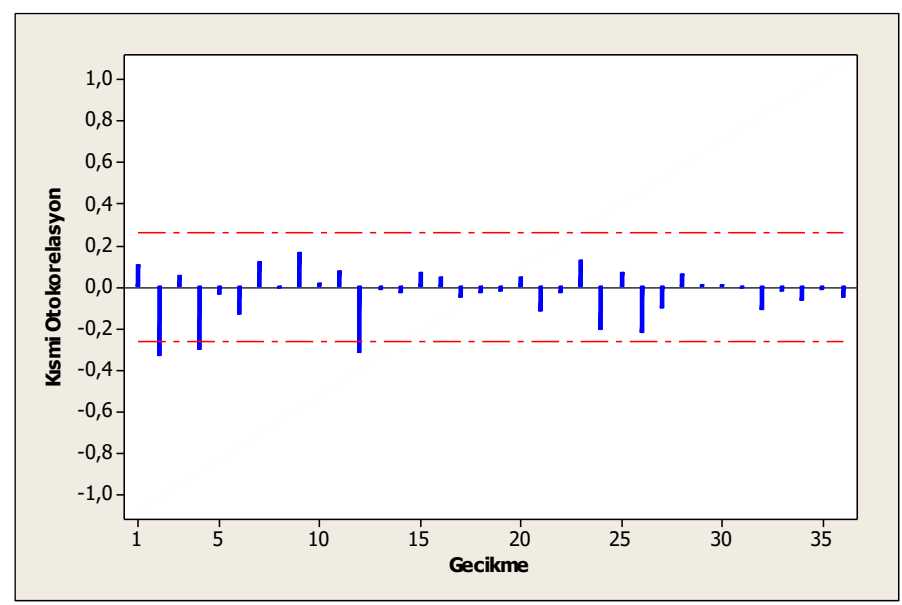

Şekil 7. Normal Düzeyde İkinci Dereceden ve Mevsimsel Farkları Alınmış Serinin Kısmi-Otokorelasyon Fonksiyonu

$\mathrm{Bu}$ aşamada, alternatif modellerin belirlenebilmesi için teorik ARIMA modellerine ait otokorelasyon ve kısmi otokoreasyon grafiklerinden faydalanılmıştır. (Hanke ve Wichern, 2014: 357-359). Teorik grafiklerin incelenmesi neticesinde, ARIMA $(1,2,1)(0,1,1)_{12}$ veya ARIMA $(1,2,1)(1,1,0)_{12}$ modellerinin uygun olabileceği sonucuna varılmıştır. Alternatif modellere ait tahmin parametreleri Tablo 4 ve Tablo 5.'de verilmiştir.

Tablo 4. ARIMA $(1,2,1)(0,1,1)_{12}$ Modelinin Tahmin Parametreleri

\begin{tabular}{|l|l|l|l|l|}
\hline \multicolumn{5}{|l|}{ Parametre Tahmin Verileri } \\
\hline Değişken & Katsay1 & Std.Hata & T-ist. & P \\
\hline AR(1) & $-0,6312$ & 0,1126 & $-5,61$ & 0 \\
\hline MA(1) & 0,923 & 0,0628 & 14,71 & 0 \\
\hline SMA(12) & 0,6455 & 0,1969 & 3,28 & 0,002 \\
\hline SS & $2,54808 E+12$ \\
\hline MS(OHK) & 46.328 .742 .016 \\
\hline Ljung-Box Ki-Kare İstatistiği \\
\hline Gecikme & 12 & 24 & 36 & 48 \\
\hline Ki-Kare & 5,8 & 17,5 & 27,4 & 42,7 \\
\hline DF & 9 & 21 & 33 & 45 \\
\hline P-değeri & 0,716 & 0,679 & 0,742 & 0,57 \\
\hline \multicolumn{5}{|l}{} \\
\hline
\end{tabular}


Parametrelerin istatistiksel anlamlılığını test etmek için, Tablo 4'ün ilk bölümde yer alan veriler analiz edilmiştir. Analiz neticesinde, ARIMA $(1,2,1)(0,1,1)_{12}$ modeline ait parametrelerin istatistiksel olarak anlamlı olduğu $(\mathrm{p}<0.05)$ görülmektedir. Ayrıca, model uygunluğunun genel kontrolü "Ljung-Box Q" istatistiği dikkate alınarak Ki-Kare testi ile sağlanmıştır. Tablo 4'den modelin, ihracat gelirini tahmin etmek için uygun olduğu ( $\mathrm{p} \geq 0.05)$ anlaşılmaktadır. Aynı durum, istatistikleri Tablo 5 ile verilmiş olan ARIMA $(1,2,1)(1,1,0)_{12}$ model için de geçerlidir.

Tablo 5. ARIMA $(1,2,1)(1,1,0) 12$ Modelinin Tahmin Parametreleri

\begin{tabular}{|l|l|l|l|l|}
\hline \multicolumn{5}{|l|}{ Parametre Tahmin Verileri } \\
\hline Değişken & Katsay1 & Std.Hata & T-ist. & P \\
\hline AR(1) & $-0,6661$ & 0,1022 & $-6,52$ & 0,000 \\
\hline SAR(12) & $-0,4139$ & 0,1518 & $-2,73$ & 0,009 \\
\hline MA(1) & 0,9562 & 0,0551 & 17,36 & 0,000 \\
\hline SS & $2,74674 \mathrm{E}+14$ \\
\hline MS(OHK) & 49.940 .812 .328 \\
\hline Ljung-Box- Ki-Kare İstatistiği \\
\hline Gecikme & 12 & 24 & 36 & 48 \\
\hline Ki-Kare & 4,9 & 19,1 & 29,2 & 44 \\
\hline DF & 9 & 21 & 33 & 45 \\
\hline P-değeri & 0,84 & 0,577 & 0,657 & 0,515 \\
\hline
\end{tabular}

Önerilen modellerin uygunluğunu test etmenin diğer bir yolu ise model hatalarına ait otokorolesyon ve kısmi otokorelasyon grafiklerinin incelenmesidir. Otomotiv ihracat gelirinin tahmin edilmesi amaciyla geliştiriken modellere ait otokorelasyon ve kısmi otokorelasyon grafikleri Şekil 8 ve Şekil 9' da verilmiştir.

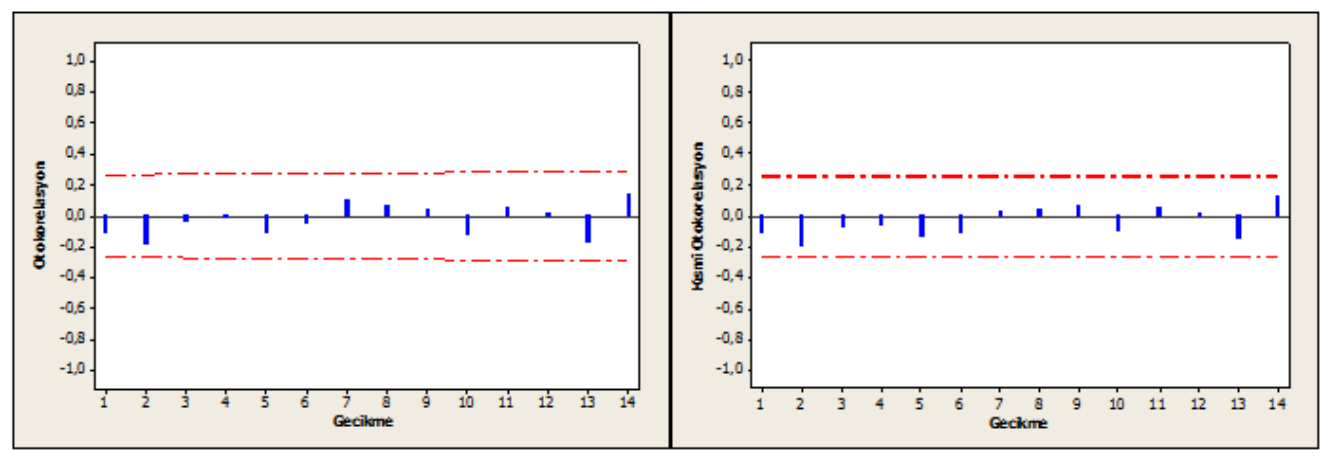

Şekil 8. ARIMA $(1,2,1)(0,1,1)_{12}$ Modelinin Tahmin Hataları Otokorelasyon ve Kısmi Otokorelasyon Grafikleri

Şekil 8 incelendiğinde, bütün otokorelasyon değerleri kontrol limitleri arasında olduğu ve dolayısıyla hatalar arasında korelasyon olmadığı yani hataların rassal olduğu sonucuna varılmıştır. Aynı durum, otokorelasyon ve kısmi otokorelasyon grafiği Şekil 9' de verilmiş olan ARIMA $(1,2,1)(1,1,0)_{12}$ modeli içinde geçerlidir.

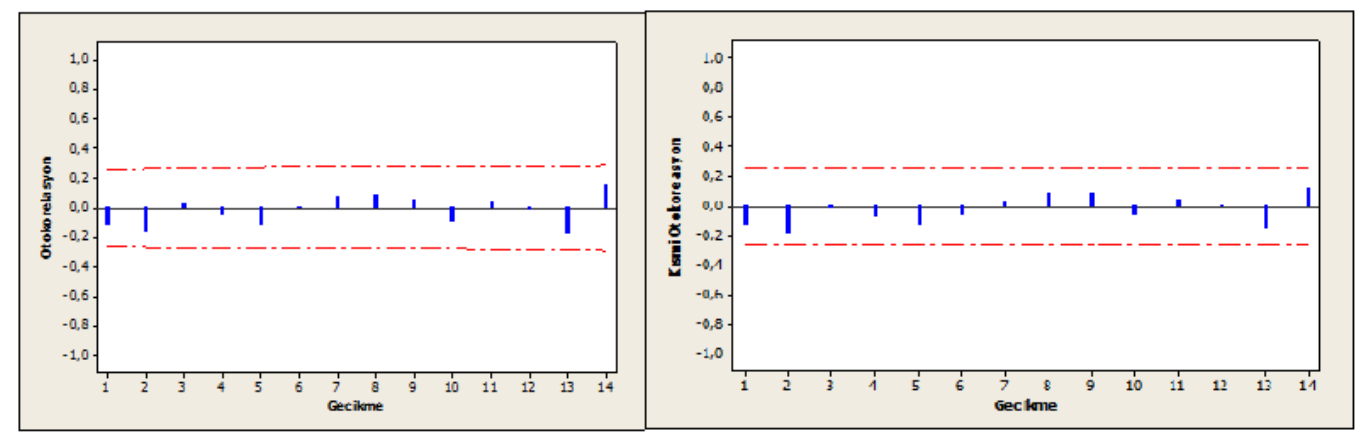

Şekil 9. ARIMA $(1,2,1)(1,1,0)_{12}$ Modelinin Tahmin Hataları Otokorelasyon Ve Kısmi Otokorelasyon Grafikleri 
$\mathrm{Bu}$ sonuçlar 1şı̆̆ında, önerilen modellerin mevcut zaman serisinin gelecekteki değerlerini tahmin etmede uygun olduğu sonucuna varılmıştır. Alternatif modeller arasında bir seçim yapabilmek için ortalama hata karesi (OHK) değerleri kıyaslanmıştır. OHK değerleri daha küçük olduğu için ARIMA $(1,2,1)(0,1,1)_{12}$ modeli tercih edilmiştir. Ayrıca modelin mutlak ortalama yüzde hata $(\mathrm{MOYH})$ değeri geçmiş hata değerleri dikkate alınarak hesaplanmış ve $\% 8.39$ olarak elde edilmiştir. Lewis (1982) çalışmasında, MOYH değeri \%10'un altında olan modellerin yüksek doğruluk derecesine sahip modeller olarak kabul edilebileceğini belirtmişlerdir (Karahan, 2015). Mevcut zaman serisi için ARIMA $(1,2,1)(0,1,1)_{12}$ modeli kullanılarak tahmin edilen 2019 yılı aylık otomotiv ihracat gelirleri ve $\% 95$ güven aralıkları Tablo 6'da verilmiştir.

Tablo 6. ARIMA $(1,2,1)(1,1,0)_{12}$ modeli ile elde edilen tahmin değerleri $(1000 \$)$

\begin{tabular}{|l|l|l|l|l|l|l|l|}
\hline \multirow{2}{*}{ Ay } & \multirow{2}{*}{ Tahmin } & \multicolumn{2}{|l|}{ \%95 güven aralı̆̆ ile } & \multirow{2}{*}{ Ay } & \multirow{2}{*}{ Tahmin } & \multicolumn{2}{c|}{$\% 95$ güven aralı̆ı ile } \\
\cline { 3 - 4 } \cline { 7 - 8 } & & Alt Limit & Üst Limit & & & Alt Limit & Üst Limit \\
\hline Ocak & 2349977 & 1928019 & 2771935 & Temmuz & 2530808 & 1609709 & 3451907 \\
Şubat & 2580651 & 2118657 & 3042645 & Ağustos & 1813638 & 809557 & 2817719 \\
Mart & 2895547 & 2304755 & 3486339 & Eylül & 2420932 & 1328747 & 3513118 \\
Nisan & 2656990 & 2000152 & 3313829 & Ekim & 2653029 & 1474311 & 3831747 \\
Mayıs & 2629504 & 1875226 & 3383783 & Kasım & 2608692 & 1340738 & 3876646 \\
Haziran & 2572360 & 1740642 & 3404078 & Aralık & 2432002 & 1074583 & 3789420 \\
\hline
\end{tabular}

TIMM internet sayfasında, 2019 yılı için ilan edilen gerçek otomotiv ihracat rakamları (TiM, ty.) ve önerilen model ile elde edilen tahmin değerleri Tablo 7' de verilmiştir.

Tablo 7. 2019 yılı gerçekleşen ve tahmin edilen otomotiv ihracat değerleri(1000\$)

\begin{tabular}{|l|c|c|}
\hline \multicolumn{1}{|c|}{ Ay } & Tahmin & Gerçekleşen Değer \\
\hline Ocak & 2349977 & 2327912 \\
Şubat & 2580651 & 2544854 \\
Mart & 2895547 & 2883376 \\
Nisan & 2656990 & 2616597 \\
\hline
\end{tabular}

2019 yılı için açıklanan ocak, şubat, mart ve nisan ayı otomotiv ihracat rakamlarının, tahmin edilen değerlere oldukça yakın olduğu görülmektedir. Gerçekleşen ihracat değeri açıklanan aylar dikkate alınarak hesaplanan MOYH, \%1,08'dir. Bu durumda, açıklanan veriler dikkate alındığında, önerilen ARIMA modelinin iyi bir tahmin edicidir.

\section{Sonuç}

Otomotiv sektörü, etki alanının genişliği ve diğer sektörlere olan katkısıyla modern ekonominin gelişiminde geniş ve önemli bir yere sahiptir (Ölekli, 2018). Türkiye otomotiv sektörü, ülke ihracatının öncüsü olan sektörlerdendir ve ekonomiye katkısı oldukça yüksektir. Uygun talep tahmini metodu ile elde edilecek talep verileri, sektörün ileriki dönemler için alacağı yatırım kararlarında, ihracat hedeflerinin daha gerçekçi belirlenmesinde ve hatta bu konudaki ülke stratejisinin ortaya konulmasında önemli bir girdi niteliği taşıyacaktır.

Mevcut çalışmada, Türkiye otomotiv endüstrisi ihracat gelirini tahmin eden en uygun ARIMA modelinin ortaya konması hedeflenmiştir. Bu amaçla, TİM tarafından açılanan 2013-2018 yılları arası aylık otomativ ihracat geliri verileri kullanılmıştır. Uygun ARIMA modelini belirleme metodolojisinin temel varsayım ve adımları izlenerek, aylık otomotiv sanayi ihracat geliri serisini en iyi açıklayan modelin ARIMA $(1,2,1)(0,1,1)_{12}$ modeli olduğu ortaya konmuştur. Önerilen model kullanılarak 2019 yılına ait 12 aylık tahmin değerleri elde edilmiştir. Önerilen modelin doğruluk derecesini belirlemek için MOYH ölçütü kullanılmıştır. 2019 yılına ait gerçekleşen değerler dikkate alınarak MOYH hesaplanmış ve \%1,08 gibi oldukça düşük bir değer olduğu görülmüştür. Lewis (1982)' in çalışmasında belirtildiği gibi MOYH değeri $\% 10$ 'un altında olan modellerin yüksek doğruluk derecesine sahip modeller olarak kabul edilmektedir. (Karahan, 2015). Bu noktodan hareketle, önerilen ARIMA modelinin yüksek doğruluk derecesine sahip bir tahmin edici olduğu ortaya konmuştur. Buna ek olarak, sonraki çalışmalarda otomotiv sanayi ihracat gelirlerine etki edecek diğer değişkenleri de dikkate alan yapay sinir ağları veya regresyon analizleri gibi yöntemler kullanılarak tahmin gerçekleştirilebilir ve sonuçlar kıyaslanabilir. 
Otomotiv endüstrisi 2018'de 31 milyar 568 milyon 469 bin dolarlık ihracat değeri elde ederek, en fazla ihracat gerçekleştirilen sektör olmuştur (TIM, ty.). ARIMA $(1,2,1)(0,1,1)_{12}$ modeli ile elde edilen tahminler neticesinde 2019 y1l toplam ihracat geliri beklentisi, 30 milyar 144 milyon 130 bin dolar olarak elde edilmiştir. Küresel ekonomi ve ticarette 2019 yılında beklenen yavaşlama dikkate alındığında, ihracatta yıllardır lider sektör olan otomotiv sektöründeki ihracat hedeflerinin sağlanabilmesi ve yükselme trendini devam ettirebilmesi için mevcut pazarlarda payın genişletilmesi ve yeni pazarlara erişim ile ürün çeşitliliğinin artırılması önemli olacaktır(TİM, ty).

Ayrıca KPMG tarafindan hazırlanan 2019 yılı sektör raporun da otomotiv sektörünün karşılaştığı diğer zorluklar; düşük karbon emisyonlu, çevre dostu hibrit ve elektrikli araçların daha çok tercih edilmesinin yarattığı talep değişimi, İngiltere'nin Avrupa Birliği'nden ayrılma süreci, küresel ticaretteki korumacı eğilimler ve rekabeti düzenleyen ve tüketici haklarını koruyan yasal gelişmelerin getirdiği yeni maliyetler olarak sıralanmıştır. Bununla birlikte aynı raporda, yerli otomobil hedefi ile Türkiye'nin yeni nesil araçlara yönelik şansını yükselmesi ve yeni nesil araçlara ilişkin ciddi bir yatırım ikliminin daha fazla artması sektörün Türkiye'deki güçlü yönleri olarak vurgulanmıştır (KPMG, ty.). Bu açıdan, özellikle düşük karbon emisyonlu, çevre dostu hibrit ve elektrikli araçların üretiminin yapılacağı yerli otomobil üretimim önümüzdeki yıllar için ihracat değerinin arttırılmasında önemli katkı sağlayacağı düşünülmektedir.

\section{KAYNAKÇA}

Bedir, A.(2002). Türkiye'de otomotiv sanayii gelişme perspektifi. Erişim adresi file:///C:/Users/asusp/Downloads/gelisme\%20(2).pdf

Chaiwuttisak, P. (2008). Forecasting Export Value in the Automobile Industry. 5th International Conference on Business and Industrial Research (ICBIR), Bangkok, Thailand.

Co, H.C., Boosarawongse, R. (2007). Forecasting Thailand's rice export: Statistical techniques vs. artificial neural networks. Computers \& Industrial Engineering, vol. 53, 610-627.

Duru, Ö.(2007). Zaman Serileri Analizinde ARIMA Modelleri ve Bir Uygulama, Yüksek Lisans Tezi. İstanbul Üniversitesi, Sosyal Bilimler Enstitüsü.

Ersungur, Ş.M., Kızıltan, A. \& Polat, Ö. (2006). ARIMA Tipi Parametrik İfadeli Modeller ile 2006 Y1lı İhracat ve İthalat Öngörüsü. EKEV Akademi Dergisi, Sayı.10, 297-307.

Esen, N., \& Bayram, B.Ç. The forecasting of the exports and imports of paper and paper products of Turkey using BoxJenkins method. Eurasian Journal of Forest Science, vol. 7, no.1, 54-65.

Farooqi, A. (2014). ARIMA Model Building and Forecasting on Imports and Exports of Pakistan. Pakistan Journal of Statistics and Operation Research, vol.10, no.2, 157-168.

Hanke, J.E. \& Wichern, D. (2014). Business Forecasting. England: Pearson Education.

Karahan, M. (2015). Yapay Sinir Ağları Metodu İle İhracat Miktarlarının Tahmini: ARIMA ve YSA Metodunun Karşılaştırmalı Analizi. Ege Academic Review, vol.15, no.2, 165-172.

Kargbo, J.M. (2007). Forecasting Agricultural exports and imports in South Africa. Applied Economics, vol. 39, 20692084.

Keck, A., Raubold, A. \& Truppia, A. (2010). Forecasting International Trade: A time Series Approach. OECD Journal: Journal of Business Cycle Measurement and Analysis, vol.2009, no.2, 157-176.

KPMG (t.y.), 2019 Yılı Otomotiv Sektör Raporu, Erişim adresi https://home.kpmg/tr/tr/home/gorusler/2019/04/sektorelbakis-2019-otomotiv.html.

Lu, J. (2015). Forecasting of U.S. Total Textiles and Apparel Export to the World in Next 10 Years (2015-2020). Journal of Textile and Apparel, Technology and Management, vol.9, no.2, 1-8.

Otomativ Sanayii Derneği (2018). Erişim adresi http://www.osd.org.tr/haberler/ekim-2018-otomotiv-sonuclari-aciklandi

Ozbek, A., Akalın, M., Topuz, V. ve Sennaroglu, B. (2011). Prediction of Turkey’s Denim Trousers Export Using Artificial Neural Networks and the Autoregressive Integrated Moving Average Model. Fibres \& Textiles in Eastern Europe, vol.19, no.3, 10-16.

Özek, T. (2010). Zaman Serisi Modelleri Üzerinde Bir Simülasyon Çalışması, Yüksek Lisans Tezi, Selçuk Üniversitesi, Fen Bilimleri Enstitüsü. 
Karakaş, E. / Journal of Yasar University, 2019, 14/55, 318-328

Ölekli, H. (2018). Otomotiv: sektörel bakış, KPMG Türkiye. Erişim adresi http://www.osd.org.tr/sites/1/upload/files/sektorel-bakis-2018-otomotiv-4314.pdf

Pişkin, S. (2017). Türkiye otomotiv sanayii rekabet gücü ve talep dinamikleri perspektifinde 2020 iç Pazar beklentileri. Erişim adresi https://www.taysad.org.tr/uploads/dosyalar/06-02-2017-09-59-170206Otomotiv_Sektor_Raporu_TSKB-2208.pdf

Paul, R.K., Panwar, S., Sarkar, S.K., Kumar, A., Singh, K.N., Farooqi, S. \& Choudhary, V.K. (2013). Modelling and Forecasting of Meat Exports from India. Agricultural Economics Research Review, Vol. 26, No.2, 249-255.

Türkiye İhracatçılar Meclisi (t.y.). İhracat rakamları. Erişim adresi http://www.tim.org.tr/tr/ihracat-rakamlari.html

Uysal, H., \& Karabat, S. (2017). Forecasting and Evaluation for Raisin Export in Turkey. BIO Web of Conferences 40th World Congress of Vine and Wine. https://doi.org/10.1051/bioconf/20170903002.

Wang, C. (2011). A Comparison Study between Fuzzy Time Series Model and ARIMA Model for Forecasting Taiwan Export. Expert Systems with Applications, vol. 38, no.2011, 9296-9304.

Wong, H.L., Tu, Y.H. \& Wang, C.C. (2010). Application of Fuzzy Time Series Models for Forecasting the Amount of Taiwan Export. Expert Systems with Applications, vol. 37, no. 2010, 1465-1470. 